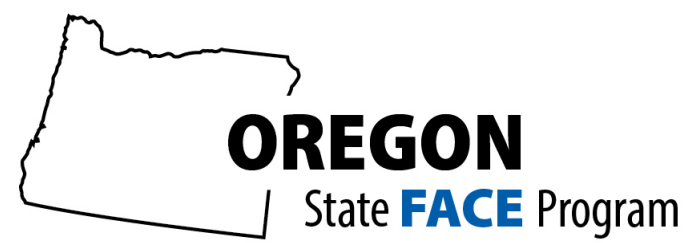

Fatality Assessment \& Control Evaluation

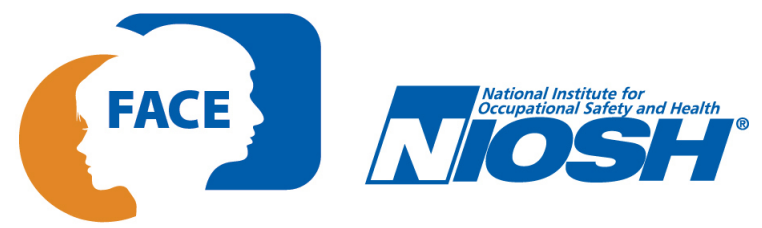

Oregon Institute of Occupational Health Sciences • Oregon Health \& Science University 3181 SW Sam Jackson Park Rd. L606 • Portland, OR 97239 • 503-494-3940

REPORT\#: $20180 R 030$

REPORT DATE: July 8, 2020

INCIDENT HIGHLIGHTS

DATE:

March 6, 2018

TIME:

11:38 AM

VICTIM:

49-year old non-Hispanic

white male pipefitter

INDUSTRY/NAICS CODE:

Construction/236220

EMPLOYER:

Commercial construction

subcontractor

SAFETY \& TRAINING:

Inadequate training and

irregular safety meetings

SCENE:

Water tank storage facility for fire suppression near large data center in a rural area

LOCATION:

Oregon

EVENT TYPE:

Struck by object under pressure

\section{Pipefitter Struck by Pressurized Pipe and Killed}

\section{SUMMARY}

On March 6, 2018, a 49-year-old pipefitter was hit in the chest by a pressurized 12 -inch diameter polyvinyl chloride (PVC) pipe during a hydrostatic pressure test of a fire suppression system. The sudden pipe movement was attributed to a pipe joint connection failure in a buried section of the pipeline. The failure was due to torque shear bolts at the joint connection that were not tightened, which was missed during the utility installation process and the work inspection prior to the incident.

\section{CONTRIBUTING FACTORS}

Key contributing factors identified in this investigation include:

- A schedule delay due to design change, and schedule pressure.

- Lack of task checklists for key testing and inspection processes.

- Deviation from planned procedures.

- Inadequate safety communication.

- Inadequate training.

\section{RECOMMENDATIONS}

To help prevent similar occurrences, employers should:

- Employers should ensure employees do not work on pressurized water systems.

- Pipe systems should be pressure-tested and inspected before pipes are backfilled. Use checklists during tasks and the inspection process to reduce risk of overlooking critical steps that could endanger workers.

- Prime contractors should establish a realistic project schedule in collaboration with subcontractors.

- Prime contractors should develop and follow a communication plan so that subcontractors are made aware of project design modifications in a timely manner and to work out how design changes will impact project schedule, so as not to compromise workplace safety.

- Employers should provide written procedures to employees prior to performing the work, and ensure employees receive adequate training so they understand the hazards and how to execute procedures safely. 


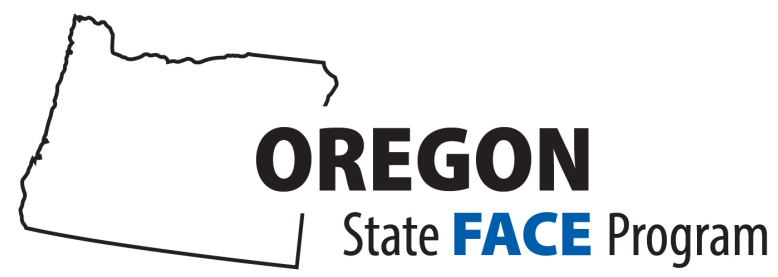

Fatality Assessment \& Control Evaluation

Oregon Institute of Occupational Health Sciences • Oregon Health \& Science University

3181 SW Sam Jackson Park Rd. L606 • Portland, OR 97239 • 503-494-3940
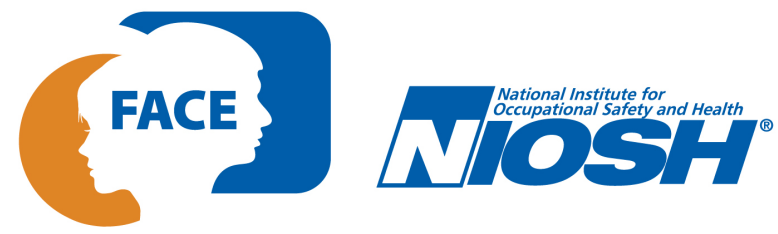

\section{Oregon Fatality Assessment and Control Evaluation Program}

The Oregon Fatality Assessment and Control Evaluation (OR-FACE) Program is a project of the Oregon Institute of Occupational Health Sciences at Oregon Health \& Science University (OHSU). OR-FACE is supported by a cooperative agreement with the National Institute for Occupational Safety and Health (NIOSH) (grant \#U60OH008472) through the Occupational Public Health Program (OPHP) of the Public Health Division of the Oregon Health Authority. ORFACE reports are for information, research, or occupational injury control only. Safety and health practices may have changed since the investigation was conducted and the report was completed. Persons needing regulatory compliance information should consult the appropriate regulatory agency.

OR-FACE supports the prioritization of safety interventions using a hierarchy of safety controls, where top priorities are hazard elimination or substitution, followed by engineering controls, administrative controls

(including training and work practices), and personal protective equipment.

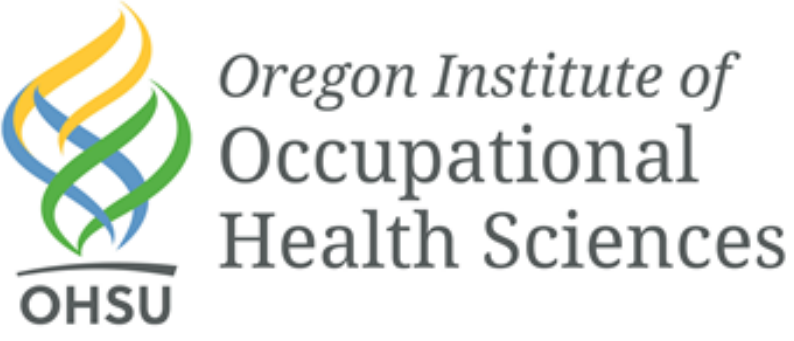




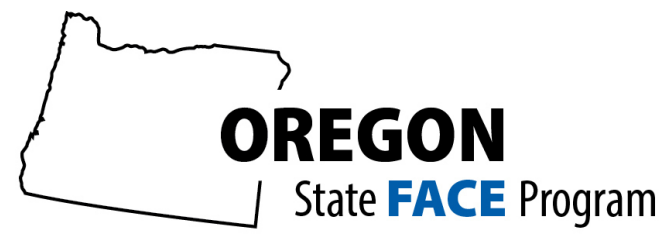

Fatality Assessment \& Control Evaluation

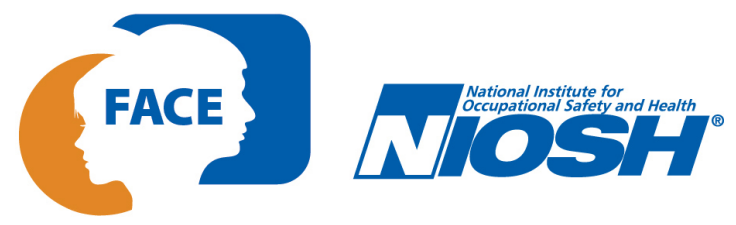

Oregon Institute of Occupational Health Sciences • Oregon Health \& Science University

3181 SW Sam Jackson Park Rd. L606 • Portland, OR 97239 • 503-494-3940

\section{SUMMARY}

On March 6, 2018, during a hydrostatic pressure test of a fire suppression system, a subcontracting pipefitter was struck by a 64-inch long, 12-inch diameter vertical section of a pressurized PVC pipe. The pipe thrust upward approximately ten inches toward the decedent's chest, striking the impact driver he was using to tighten flange bolts on the end cap of the pipe. The pipe came loose under pressure because the torque shear bolts on the mechanical joint restraining gland had not been tightened at all. The gland connected the vertical pipe to the flange of a horizontal pipe running parallel to ground level, about 4 feet deep. The pipefitter was knocked backward and fell onto a rebar grid surrounding the pipe. Co-workers attempted to render aid. A coworker checked for a pulse and when no pulse was found, chose not to attempt cardio-pulmonary resuscitation (CPR) chest compression as it was suspected the decedent's ribs were broken. The co-worker continued with rescue breaths and the site safety supervisor used an automated external defibrillator (AED), but could not revive the decedent. While aid was being rendered, other co-workers called 911 and the prime contractor's safety coordinator. The pipefitter was pronounced dead at the scene by Emergency Medical Services (EMS). The failed pipe connection had been backfilled prior to the hydrostatic pressure test. A visual inspection by qualified persons was performed prior to backfilling, but inspection documentation was not available. Workers reported mid-project design changes that led to schedule pressure from the primary contractor as a reason for backfilling the work before the pressure test was performed. There was no record that the decedent had received training on how to perform the hydrostatic pressure test safely, and no record that the employer's test procedure and checklists were followed on the day of the incident. The subcontractor was cited and fined for not ensuring workers were properly trained and supervised in the safe operation of tools, equipment, process or practice.

\section{INTRODUCTION}

On March 6, 2018 at approximately 11:38am, as part of a three-man crew, a 49-year old Non-Hispanic White male pipefitter was killed while performing a hydrostatic pressure test of a fire suppression system for a data center under construction in Eastern Oregon. The decedent, an employee of a subcontractor, was testing the connection between two fire suppression tank pads when a below-ground connection of a 64-inch long, 12-inch diameter PVC pipe that was under pressure (175-190 PSI) failed. This caused the pipe to thrust upward approximately six to ten inches at high velocity, striking the impact driver the decedent was using to tighten flange bolts on the end cap of the above-ground section of the vertical riser (see Diagram 1). The torque shear bolts on the mechanical restraining gland connecting the south vertical riser to the horizontal section had not been tightened at all prior to being backfilled.

\section{Ground level}

Mechanical restraining gland (gray)

Horizontal pipe

with $90^{\circ}$ elbow
End cap flange

Vertical riser

Torque shear bolts

(blue)

Diagram 1. Schematic of vertical riser connection to horizontal section of pipe, with mechanical restraining gland and torque shear bolts. 


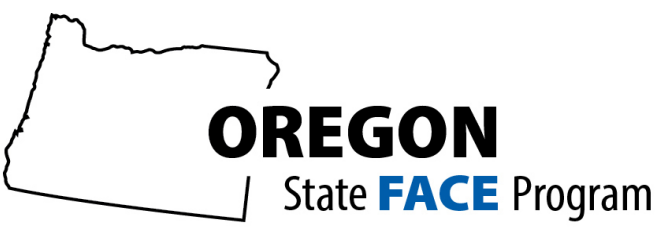

Fatality Assessment \& Control Evaluation

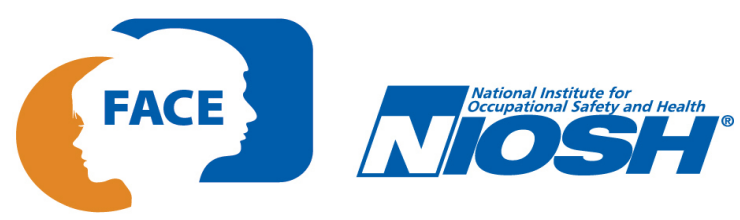

Oregon Institute of Occupational Health Sciences • Oregon Health \& Science University

3181 SW Sam Jackson Park Rd. L606 • Portland, OR 97239• 503-494-3940

The pipefitter was declared dead at the scene by EMS. The County Sheriff arrived and secured the scene. Oregon OSHA (OR-OSHA) was notified within five hours of the incident. The OR-OSHA Safety Compliance Officer (SCO) conducted a workplace fatality investigation over the following 2 months. Photographs and witness statements in this report were taken by the County Sheriff's Office or the OR-OSHA SCO. This Oregon FACE investigation was completed through collaborative work with OR-OSHA and consultation with construction industry experts at the Associated General Contractors, Oregon Columbia Chapter.

\section{EMPLOYERS}

- The prime contractor is a large, national construction engineering company and has been in business 38 years. It is not known how many employees the prime contractor had at the job site the day of the incident. The prime contractor had hired the subcontractor to excavate and build a water storage and treatment system, and a fire suppression system, at the commercial building site.

- The subcontractor that employed the decedent was an incorporated commercial building contractor. They employed 269 people in Oregon, with 45 workers on-site on the day of the incident. The subcontractor had been in business 16 years.

\section{WRITTEN SAFETY PROGRAMS and TRAINING}

The employer provided records to the OR-OSHA SCO. These include procedures for water pipe installation, competent person training for excavation and forklift for the excavation/pipe superintendent, the excavation permit, excavation/trenching inspection logs, safety meeting rosters, employee training records including training records for the decedent, records of job safety analyses, and the decedent's job application with the employer.

Documentation of daily activities related to workplace safety and employee training were minimal for both the prime contractor and subcontractor (employer), and neither could provide details of having performed checks or inspections on the buried section of pipe that was backfilled and involved in the incident.

The employer had developed a 10-page procedure for the hydrostatic pressure testing (HPT procedure) to control the hazards associated with testing, with the most current revision date of June 3, 2013 (5 years prior to the incident). The steps of the actual hydrostatic pressure test were listed as a task checklist with a sign-off column for the crew member(s) performing the test. The procedure outlined detailed steps to be followed by employees performing hydrostatic pressure tests:

1. Determine type of test for job and location, and notify proper authorities to schedule required inspections.

2. Write test procedure and calculate head pressure due to elevation variations.

3. Inspect worksite. Ensure all sections of piping has been tied together and piping system is secured [emphasis added].

4. Prepare line for test. Ensure joints are left uncoated and exposed while testing [emphasis added].

5. Prepare test equipment. 


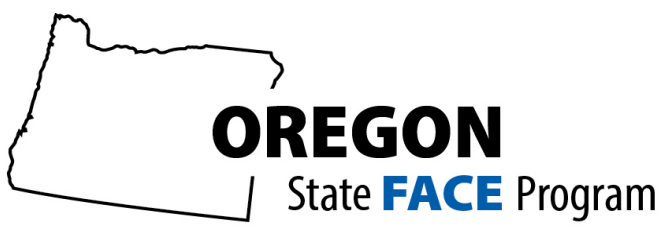

Fatality Assessment \& Control Evaluation

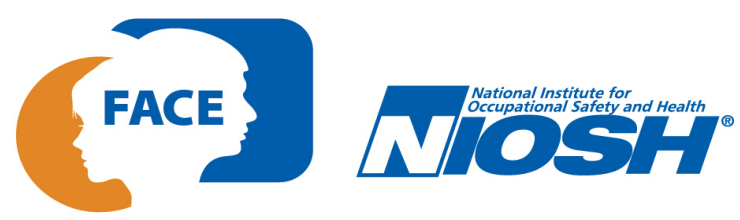

Oregon Institute of Occupational Health Sciences • Oregon Health \& Science University

3181 SW Sam Jackson Park Rd. L606 • Portland, OR 97239 • 503-494-3940

6. Establish a critical work area. Only testing personnel shall be allowed in the test area. No work may be carried out in the test area during testing.

7. Conduct a safety meeting before proceeding with test, covering the test procedure, equipment being tested, people and their responsibilities, the communication system, and the restricted area.

8. Perform the test. Adequate communication must be maintained among all personnel involved in the test. Under no circumstances will any work be carried out to repair leaks while the test section is under pressure [emphasis added]. If a leak is detected, a written search procedure must be prepared and put in place.

9. Document the test procedure and results.

10. Stop process if issues develop. Communicate what the issue is, how it needs to be addressed, and who will do the work.

However, the HPT procedure were only made available to upper management and was not included in the job safety manual. The site superintendent, foremen, field safety technician or employees at the jobsite where the incident occurred did not have access to a written copy of the HPT procedure. In fact, the excavation/pipe superintendent was not aware of the HPT procedure until after the incident. The site superintendent/project manager was aware of the HPT procedure because he found it in a copy of the company's superintendent handbook when he first was hired and assumed every superintendent had a copy. The employer did not provide training on the HPT procedure to employees performing the test, and the HPT procedure was not made available to the crew performing the test.

\section{WORKER INFORMATION}

The decedent was a 49-year old Non-Hispanic White male pipefitter and resident of Oregon. He had worked for the employer for 16 months. He reported eight years of construction experience on his application for the position he held with the employer at the time of the incident. The employer provided all records of the decedent's training, but the Pressure Testing procedure was not among them. The records show that the decedent received training in excavation, spotter training, operator qualifications, control of work standard, stop work authority, basics of workplace safety, ladder safety, biohazard safety, aerial lift safety, arc welding fire safety, portable abrasive wheel safety, spotter/working near structure, illumination, safe operation of vehicles, handling gas cylinders, proper lifting and carrying, and training on hazard identification, including the hazards associated with horseplay, working in cold weather, moving machinery, and carbon monoxide poisoning.

\section{INCIDENT SCENE}

The incident site was near a large data center facility under construction in rural Eastern Oregon. The subcontractor had been hired by the prime contractor to provide excavation; water pipe installation for the facility, as well as construction and testing of both a fire suppression system and a wastewater treatment facility; and concrete work for building walls and equipment pads. Two fire suppression tank pads were connected to a 470,000-gallon water storage tank via 12 -inch diameter pipes. The tank pads were also connected to each other via a 12-inch pipe that ran north to south below ground, with 64-inch long vertical risers at each end (see Photo 1 and Diagram 2). The vertical risers terminate within the fire suppression tank pads, which are then enclosed. 


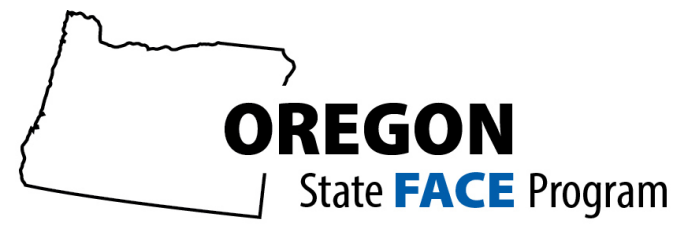

Fatality Assessment \& Control Evaluation
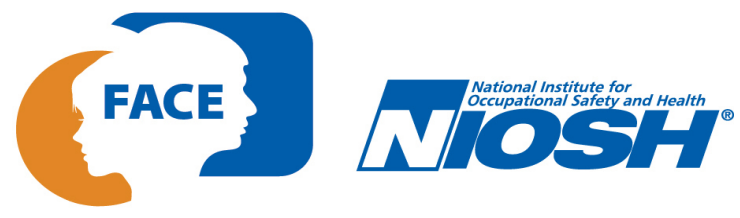

Oregon Institute of Occupational Health Sciences • Oregon Health \& Science University 3181 SW Sam Jackson Park Rd. L606 • Portland, OR 97239• 503-494-3940

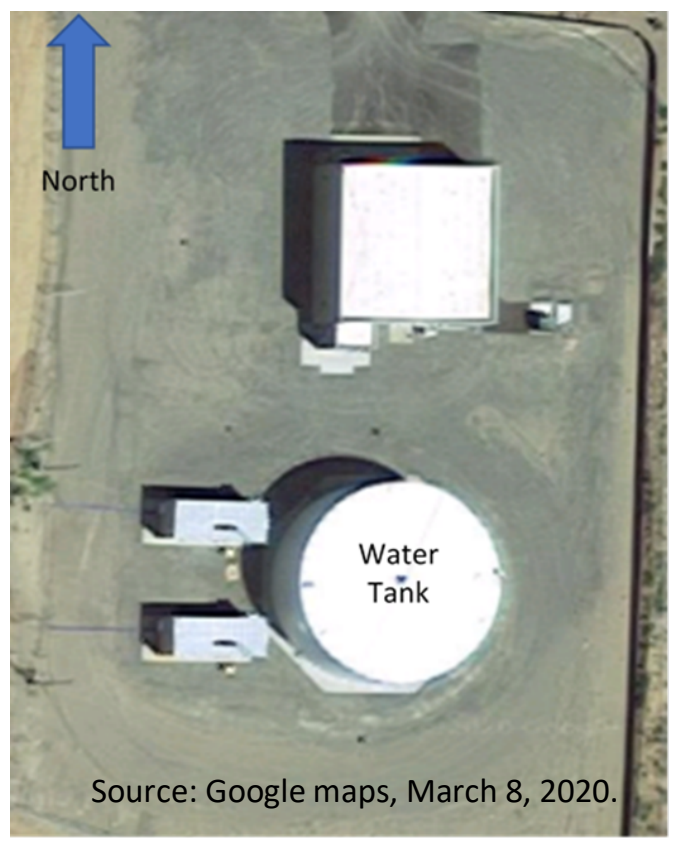

Photo 1. Incident scene, aerial view, after construction completed.

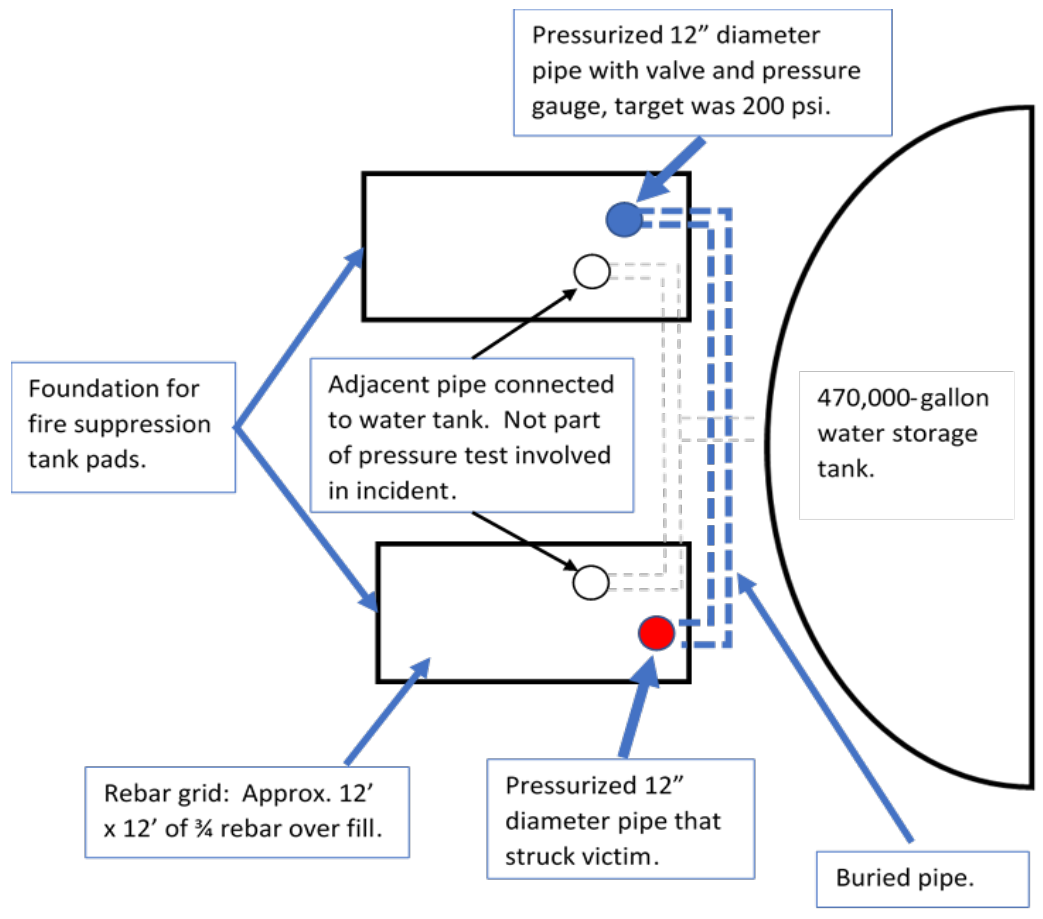

Diagram 2. Schematic of Incident scene.

On the morning of March 6, 2018, three subcontractor employees (the excavation/pipe superintendent, and two pipefitters) were performing a hydrostatic pressure test on the connecting pipe between the fire suppression tank pads. The subcontractor had already performed hydrostatic pressure tests on the 12-inch pipes between the water storage tank and the tank pads without a recorded incident.

The hydrostatic pressure test on the pipe that ran between the tank pads took place after the pipes had been backfilled and the foundation forms and rebar for the tank pads had been constructed (see Photo 2). The vertical risers were backfilled with gravel so that 48 inches of the risers were below grade and 16 inches above grade. In preparation for the hydrostatic pressure test on the morning of March 6, 2018, the north riser was capped with a threaded port to which a hydrostatic pumping unit was installed, and the south riser was capped after the pipe was filled with water and secured with flange bolts (see Photo 2).

\section{WEATHER}

The weather at the time and day of the incident was sunny, approximately 44 degrees Fahrenheit, with a 3 mph ENE wind. There had been 0 inches of precipitation recorded in the previous 24-hour period at a nearby airport [Weather Underground, 2018]. Weather is believed to not have been a factor in this incident. 


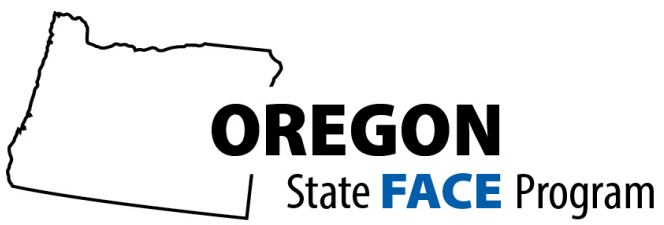

Fatality Assessment \& Control Evaluation

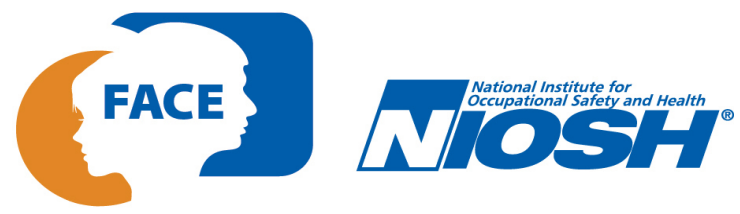

Oregon Institute of Occupational Health Sciences • Oregon Health \& Science University 3181 SW Sam Jackson Park Rd. L606 • Portland, OR 97239 • 503-494-3940

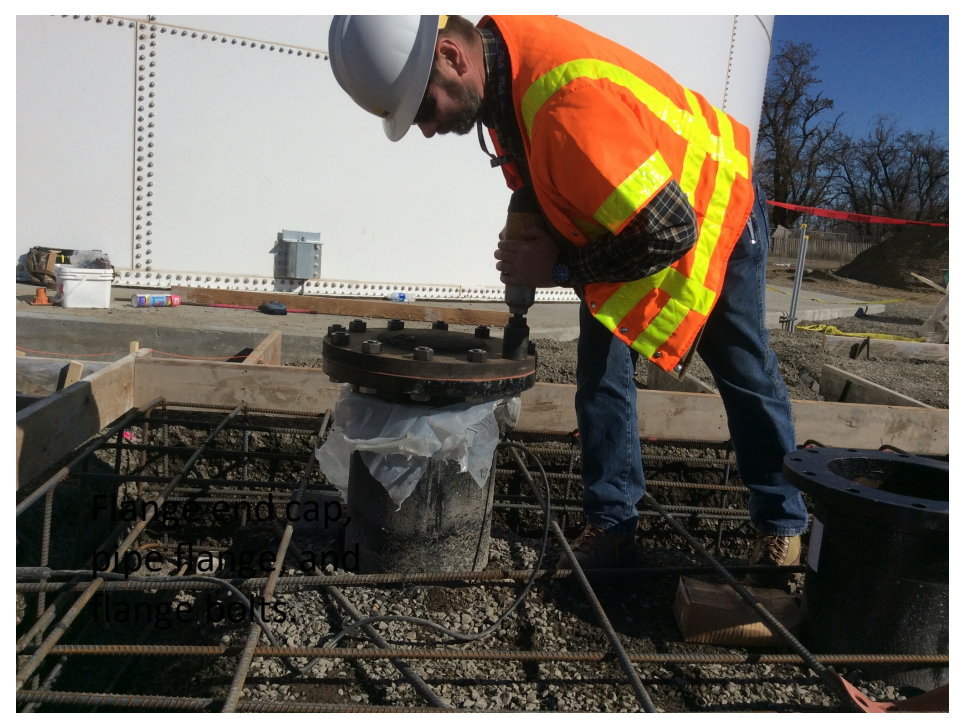

\section{Photo 2. Simulation of work performed by victim prior to} incident. Note backfill and rebar lattice.

(Photo courtesy of OR-OSHA.)

\section{INVESTIGATION}

The excavation of the pipe involved in the incident took place three days after the incident occurred, to allow time for company and manufacturer representatives to travel to the incident location and attend an investigation led by the OROSHA SCO. The OR-OSHA SCO completed the workplace fatality investigation over a 2-month period. OR-FACE completed further investigation activities, including reviewing reports, process documentation and equipment specifications, as well as consultation with construction industry experts, and follow-up communication with the OROSHA SCO, between February and May 2020.

Based on the OR-OSHA SCO interviews with the two site supervisors, the fire suppression system installation and hydrostatic pressure test plan was supposed to follow the steps listed below. To illustrate how actual work deviated from the planned work, we provide a descriptive bullet under relevant steps.

\section{Planned work:}

1) Prime contractor provides fire suppression system design specifications to the subcontractor.

2) The subcontractor and the prime contractor or owner complete and sign the subcontractor's Pressure Testing procedure checklist for pre-work specifications.

Actual work: This did not happen because the subcontractor did not have a copy of the Pressure Testing procedure at this job site, so the checklist was not available.

3) Subcontractor's excavation and pipe crew excavate as needed, and install the pipe system. 


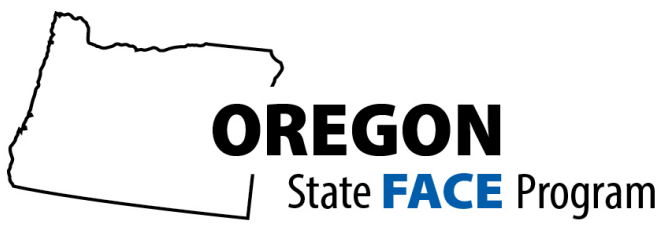

Fatality Assessment \& Control Evaluation

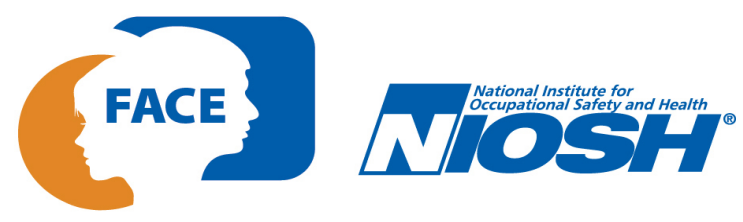

Oregon Institute of Occupational Health Sciences • Oregon Health \& Science University

3181 SW Sam Jackson Park Rd. L606 • Portland, OR 97239 • 503-494-3940

4) The subcontractor's pipe crew performs hydrostatic testing as per the subcontractor's Pressure Testing procedure, which includes a task checklist and sign-off.

Actual work: The checklist was not followed because a copy of the Pressure Testing procedure was not made available to the pipe crew. The pipe crew was also not trained in how to recognize and control the hazards associated with the hydrostatic pressure test.

a) For the hydrostatic test, the test crew attaches an air compressor to one end of the pipe system, fills the pipe system with water, caps the other end of the pipe system, lets it sit briefly, then vents the air from the system to prevent a pipe rupture. After the air is vented, the water pressure is increased towards the target 200 pounds per square inch (PSI) and then the pump is cycled on and off to see if the pipe would hold pressure.

b) If the pipe holds pressure, the pipe is depressurized, and the air compressor is removed the pipe system.

c) If the pipe doesn't hold pressure, the pipe is depressurized before measures to detect leaks are initiated. Once leaks are repaired, the test crew repeat steps $4 \mathrm{a}$ and $4 \mathrm{~b}$.

Actual work: the test crew did not depressurize the pipe before trying to correct leaks.

5) The subcontractor's concrete crew then installs thrust blocks (concrete supports) under 90-degree elbows of the horizontal section of pipe that will be approximately 48 -inches below ground upon completion. Thrust blocks prevent the pipe from moving when the pressure load is applied. To protect the connection joint from concrete, the connection joint between the vertical riser and the horizontal section is wrapped in plastic.

Subcontractor then contacts the prime contractor, the state plumbing inspector and the Fire Marshall, to inspect the pipe installation.

Actual work: Inspection took place before hydrostatic testing was completed on the tank pad pipe system, and after concrete thrust blocks were installed, in which connection joint was wrapped in plastic.

6) Once inspections are passed, the prime contractor informs the subcontractor they can backfill the pipe and pour concrete for the tank pads. The vertical risers are set into the concrete tank pads and the pads are enclosed.

Actual work: Backfill completed before hydrostatic pressure testing was completed on the tank pad pipe system.

In this particular incident, there were preventable design mistakes and procedural breaches that increased risk and led to the workplace fatality.

On March 9, 2018, with approximately 20 witnesses present including the OR-OSHA SCO, and representatives of the prime contractor and subcontractor, the south vertical riser that struck the decedent was excavated, following previously outlined and agreed-upon procedures that would maintain chain-of-custody protocols for equipment and materials. The excavation was stopped at various depths for inspection and to take photographs.

At approximately two feet of depth from top of riser, there was evidence of erosion alongside the riser, indicating a leak. At approximately four feet of depth from top of riser, plastic wrap placed around the connection between the vertical 


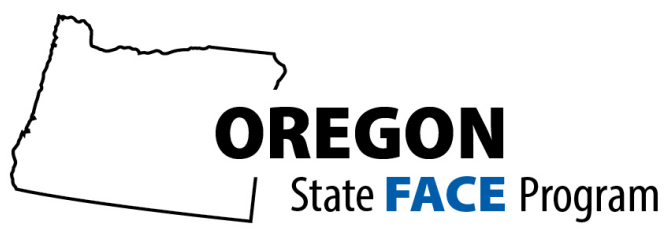

Fatality Assessment \& Control Evaluation

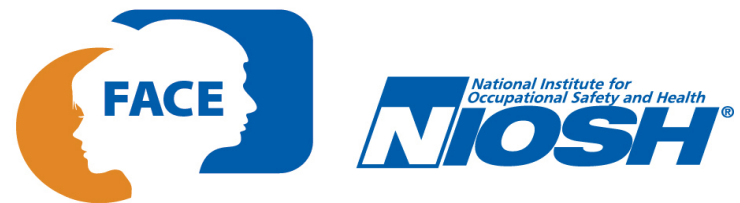

Oregon Institute of Occupational Health Sciences • Oregon Health \& Science University 3181 SW Sam Jackson Park Rd. L606 • Portland, OR 97239• 503-494-3940

riser and the 90-degree elbow of the horizontal section of the pipe was visible. The plastic wrap was placed around the riser and connection point by the crew who poured a thrust block, which is a concrete support block below the 90degree elbow of a horizontal pipe. A thrust block prevents soil compaction below the elbow that could occur from pressure cycling, which could lead to misalignment strain on the pipe connection and subsequent leaks. The plastic wrap protects the connection joint, in case future access is needed for repairs or maintenance.

At approximately six feet of depth from top of riser, the connection joint between the vertical riser and the 90-degree elbow of the horizontal pipe section was visible (See Photo 3). The 90-degree elbow had a flange with 12 silver-colored flange bolts connected to the mechanical joint restraining gland, which had 12 blue torque shear bolts to connect and hold the vertical riser to the flange on the elbow of the horizontal pipe.

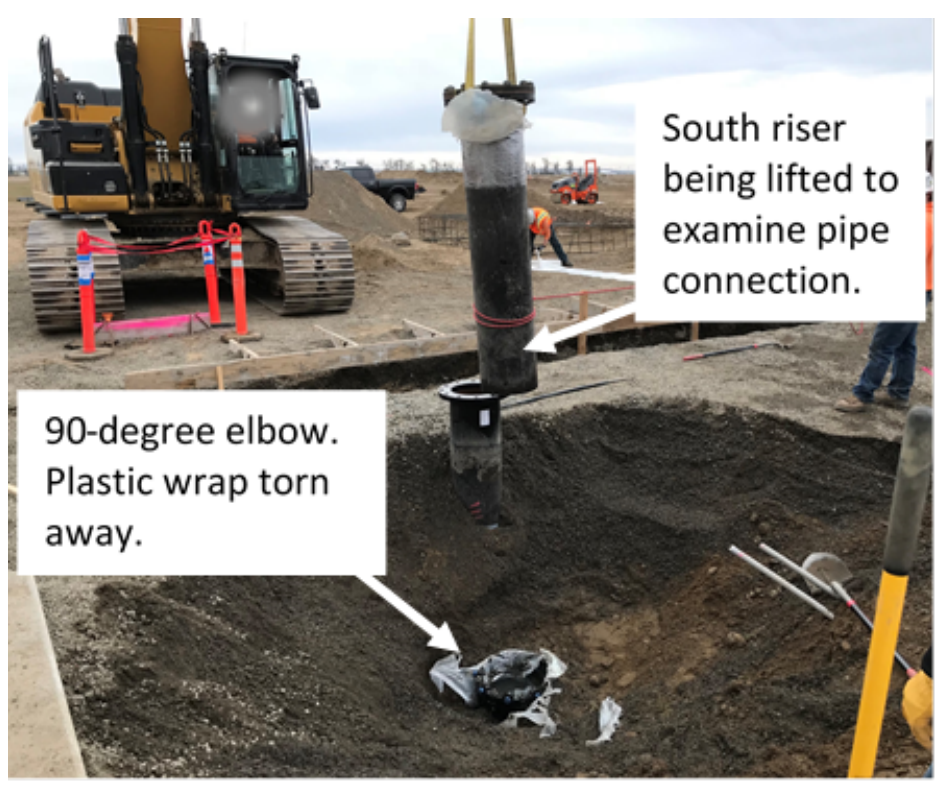

Photo 3. Post-incident excavation. South vertical riser to connection point with 90 -degree elbow of horizontal pipe section. (Photo courtesy of OR-OSHA)

The mechanical joint restraining gland ("gland") works by being bolted to a pipe flange with flange bolts, then a section of riser pipe is inserted into the gland and torque shear bolts on the gland are tightened, moving inward at an angle so that the torque shear bolts dig into the side of the pipe. The hex-heads of the torque shear bolts are made to break off when the bolts have been sufficiently tightened (see Images 1-3, EBAA Iron, Inc., 2018). 


\section{OREGON}

J State FACE Program

Fatality Assessment \& Control Evaluation
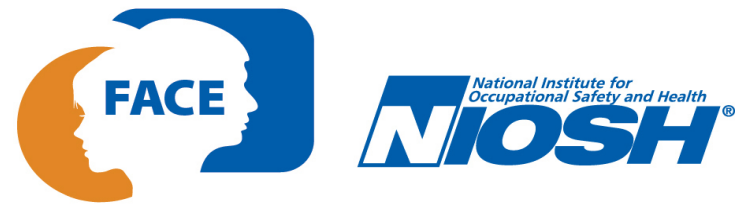

Oregon Institute of Occupational Health Sciences • Oregon Health \& Science University

3181 SW Sam Jackson Park Rd. L606 • Portland, OR 97239 • 503-494-3940

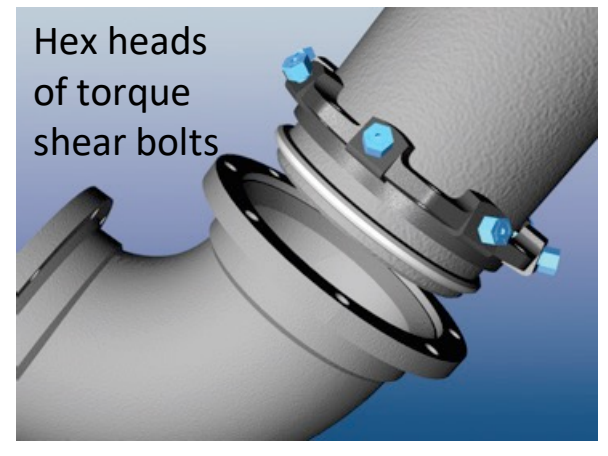

Image 1. Mechanical joint

restraining gland (dark gray, with blue torque shear bolts) fitted onto end of pipe.

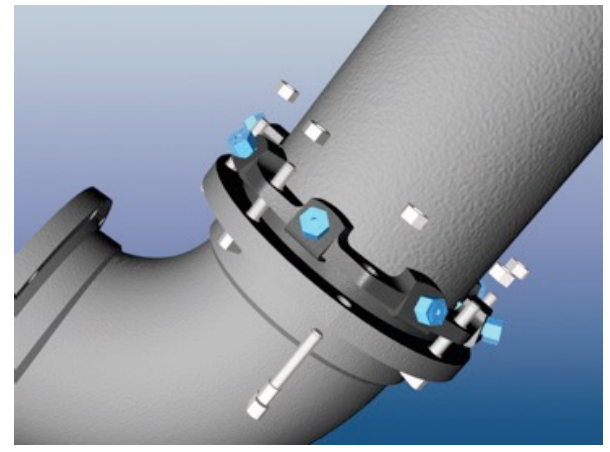

Image 2. Flange bolts (silver-colored) are inserted through elbow flange and secured to gland.

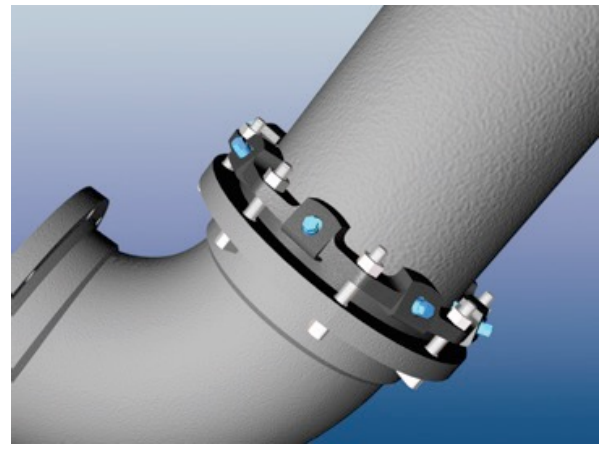

Image 3. The hex-heads of the torque shear bolts (blue) are broken off when sufficiently tightened.

When the plastic wrap was torn away, observers noticed that the hex heads of the torque shear bolts on the gland were intact, indicating that the torque shear bolts had not been tightened sufficiently (see Photo 4 ). When the south vertical riser was removed and inspected, there were no torque shear bolt marks on the pipe, which would have been visible had the torque shear bolts been tightened sufficiently (see Photo 5).

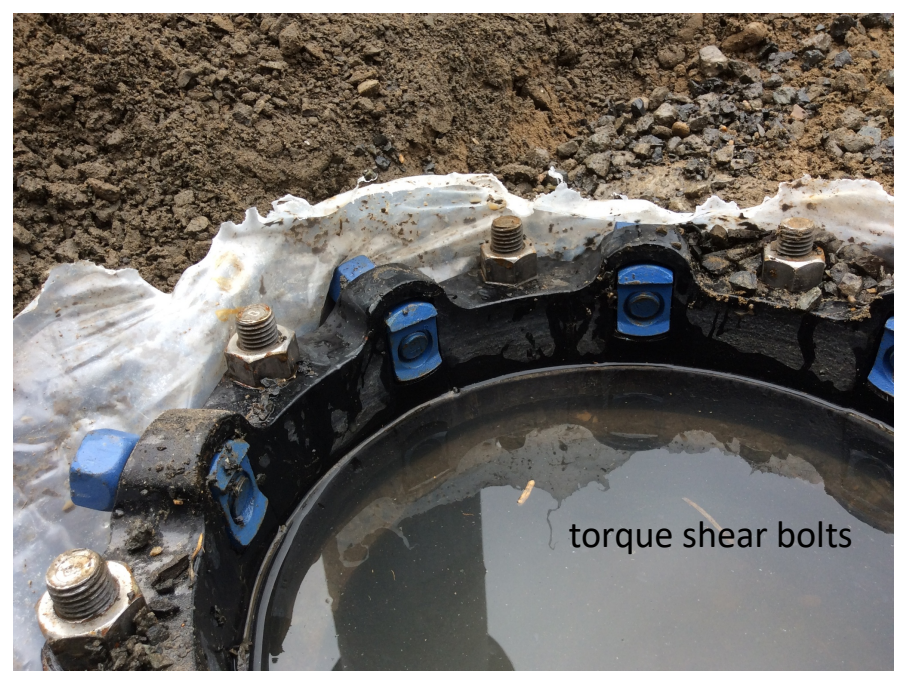

Photo 4. Flange bolts (silver) and torque shear (blue) on gland. Vertical riser has been removed. Note hex-heads of torque shear bolts are still attached.

(Photo courtesy of OR-OSHA.)

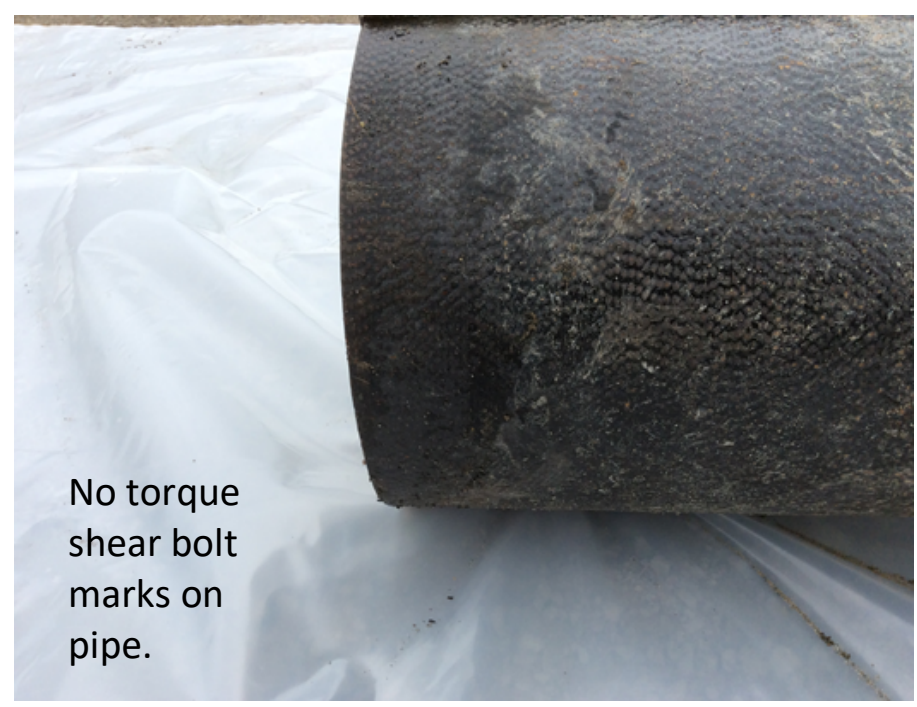

Photo 5. Bottom end of south vertical riser. Note there are no torque shear bolt marks on the outside of the pipe, indicating torque shear bolts were not tightened.

(Photo courtesy of OR-OSHA) 


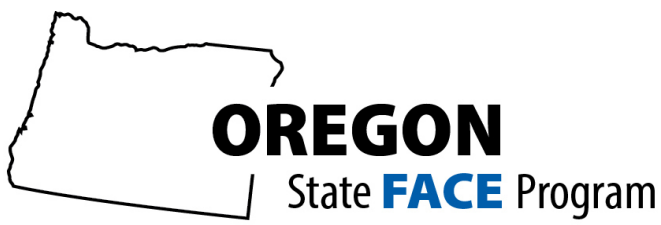

Fatality Assessment \& Control Evaluation

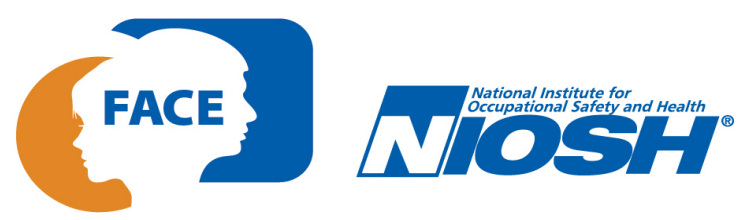

Oregon Institute of Occupational Health Sciences • Oregon Health \& Science University

3181 SW Sam Jackson Park Rd. L606 • Portland, OR 97239• 503-494-3940

As previously outlined, the process leading up to backfill included completion of the hydrostatic pressure test, followed by an inspection of the pipe system. The foreman initiated the inspection process, which involved the Fire Marshall, the State Plumbing Inspector, and the prime contractor's site supervisor. After a visual inspection and approval by Fire Marshall and State Plumbing Inspector, the prime contractor authorized a subcontractor's pipe/excavation site supervisor to backfill the area around the pipes. Those participating in the inspection process did not provide documented confirmation as to the state of the pipe connections and apparently did not ask for the hydrostatic pressure test checklist, which was not available, or the test results, which were not available because the test had not been performed. After backfilling was completed, the subcontractor's pipe/excavation supervisor realized a hydrostatic pressure test had not been performed on the pipe system between the two tank pads. He planned to run the test on this pipe system on March 6, 2018.

On the morning of March 6, 2018, there were 26 employees at the job site. A safety meeting was not held prior to the scheduled hydrostatic pressure test. The last safety meeting record provided by the employer in which the decedent took part was on February 28, 2018 and the topic was carbon monoxide poisoning.

The hydrostatic pressure test involved a hydrostatic pumping unit, which had been assembled by the pipe/excavation supervisor and the decedent. The pump was rated at 400 PSI at 600 RPM and had a 400 PSI relief valve installed on the outlet side of the pump. The pump was driven by a 4HP Honda gas engine, which had an idle speed of 1,250 RPM, over twice the rating of the pump. Once assembled, the hydrostatic pumping unit was attached the end cap of the north riser.

The employer's HPT procedure system checklist included the line item "All fittings/flanges/bolts tightened/torqued to spec?" The subsequent fields in the checklist table were labeled "No", "Yes (Date \& Initial)", and "Comments." Use of this checklist would have revealed the torque shear bolts had not been tightened sufficiently.

During the hydrostatic pressure test, the pressure was approaching the target pressure of 200 PSI, but would not hold, indicating there was a leak. The crew looked for leaks on exposed pipe flanges and observed a small amount of water between the south riser flange and the end cap (see Photo 2).

One pipefitter and the excavation/pipe superintendent returned to the hydrostatic pumping unit on the north riser. The other pipefitter (decedent) stayed at the south riser and used an electric impact driver (see simulation in Photo 2) to tighten the bolts connecting a pipe flange and end cap. The water pressure in the 12-inch pipe was between 175-190 PSI as the decedent worked his way around the flange and end cap, leaning over it to tighten flange bolts with the impact driver held close to his chest.

At approximately 11:38am, the below-ground connection joint of the south riser failed (as discovered during the subsequent investigation), causing the riser to rapidly thrust upwards approximately six to ten inches, striking the impact driver and the decedent in the chest, knocking him backwards and onto the rebar grid surrounding the riser. 


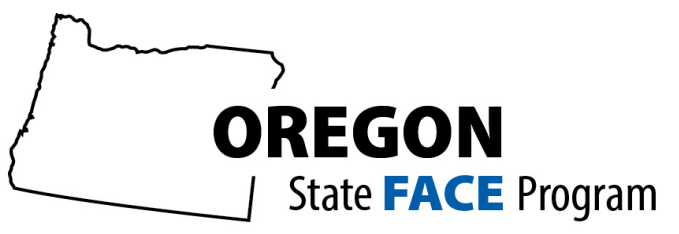

Fatality Assessment \& Control Evaluation

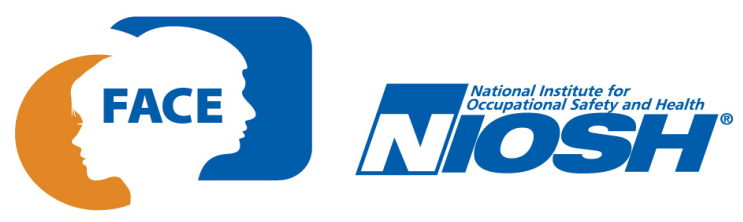

Oregon Institute of Occupational Health Sciences • Oregon Health \& Science University

3181 SW Sam Jackson Park Rd. L606•Portland, OR 97239• 503-494-3940

Several construction workers in the immediate area heard the sound of the pipe connection failure and saw the decedent fly backwards. They rushed to his aid and some carried him to level ground. Others called 911 and site safety. The site superintendent checked for a pulse and when no pulse was found, attempted cardio-pulmonary resuscitation (CPR), but did not do chest compressions as the decedent's ribs were broken. The site superintendent continued with rescue breaths. The site safety supervisor used an automated external defibrillator (AED), but could not revive the decedent. EMS personnel arrived and declared the decedent dead at the scene.

The County Sheriff arrived and secured the scene, identified the people in charge and witnesses at the job site, and called the County Medical Examiner. The regional Oregon OSHA office was notified within eight hours of the fatality.

\section{CAUSE OF DEATH}

According to the OR-OSHA report, the cause of death was blunt force trauma to the front torso causing multiple and massive internal injuries.

\section{CONTRIBUTING FACTORS}

- A schedule delay due to a design change, and schedule pressure.

- Lack of task checklists for key testing and inspection processes.

- Deviation from planned procedures.

- Inadequate safety communication.

- Inadequate training.

Occupational fatalities are typically the result of one or more contributing factors or key events in a larger sequence of events that ultimately result in a fatality.

While the direct cause of death was being struck by the vertical riser, several critical at-risk actions and inactions led to the fatal event. These included the torque shear bolts not being tightened to secure the south riser prior to hydrostatic pressure testing, inadequate inspection of the torque shear bolts that would have identified the bolts had not been tightened sufficiently, the decision to backfill the pipe before hydrostatic pressure testing was performed, and the employer permitting a leak repair on pressurized pipe.

There were several administrative or operational factors that contributed to at-risk conditions and series of events. First, design changes occurred after plans had been issued to the subcontractor, who had already installed the pipes as per the original plan. As a result of design changes affecting the placement and elevation of the vertical risers, the subcontractor had to excavate, remove, relocate, and reinstall part of the pipe system. This may have added to subcontractor crewmembers' confusion as to the state of readiness of the vertical riser for pressure testing. The north riser was installed first and secured properly, by way of the torque shear bolts on the restraining gland sufficiently tightened so that the hex heads were twisted off. The south riser was installed but not secured because the elevation of the south riser in the final design plan was awaiting confirmation from the prime contractor. A few days passed before confirmation was received, which caused a schedule delay. 


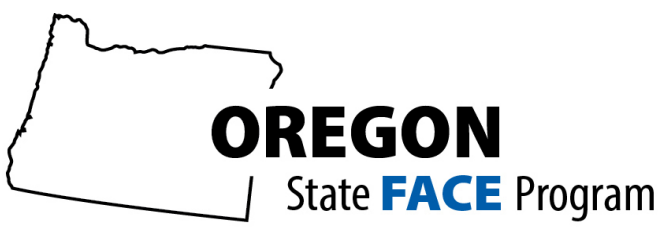

Fatality Assessment \& Control Evaluation

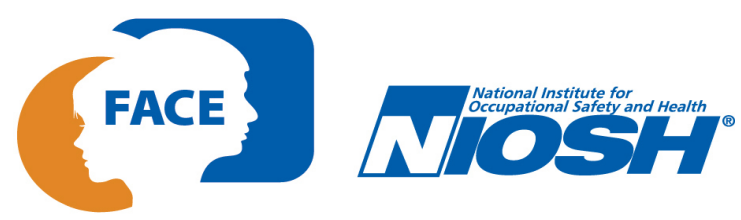

Oregon Institute of Occupational Health Sciences • Oregon Health \& Science University

3181 SW Sam Jackson Park Rd. L606 • Portland, OR 97239• 503-494-3940

Second, pressure from the prime contractor to keep the project moving forward led the subcontractor to allow the concrete crew to install the thrust blocks under the 90-degree elbow prior to the hydrostatic pressure test. The subcontractor's foreman reminded the subcontractor crews twice over the radio that the torque shear bolts on the south vertical riser needed to be tightened prior to backfill, but did not follow-up because he felt it was not his, but the pipe/excavation superintendent's responsibility. The superintendent stated he was trying to keep track of project details in his head, and ensuring the torque shear bolts were tightened was overlooked due to dealing with the design changes and schedule pressures.

Third, the inspection of the pipe connection was a visual inspection only. Documentation of the hydrostatic pressure test was not requested by the inspectors, which would have revealed the test had not taken place. Also, the connection joint between the south vertical riser and the 90-degree elbow of the horizontal section was wrapped in plastic from the thrust block installation, so actual visual inspection of this connection joint could not have taken place, or it would have revealed the torque shear bolts were intact.

Fourth, neither the prime contractor nor subcontractor maintained anything but minimal documentation regarding inspection details, approvals for pipe installations, backfilling or pressure testing. There were no checklists or other records of the connection of the south vertical riser needing to be secured with the torque shear bolts, even though it had not been secured for over a week and was made known to supervisors and crew over the radio twice by the foreman. It is not known if the decedent heard the announcements by the foreman about the untightened torque shear bolts on the south riser prior to conducting the hydrostatic pressure test.

Fifth, there was no record the decedent had been trained in hydrostatic pressure testing. The employer developed the procedure for hydrostatic pressure testing and made copies of the procedure available to superintendents, but there are no records indicating the procedure was made available to the employees performing the hydrostatic test. If he had been trained, he may not have attempted a repair on a pressurized system, or refused such work if his employer asked him to perform such work.

In summary, the unrecognized hazards or inadequately controlled exposures were contributing factors to this incident, including:

- A schedule delay caused by changes to design plans that were not communicated to subcontractor in a timely manner, leading to schedule pressure by the prime contractor.

- Lack of task checklists for key testing and inspection processes.

- Lack of access to, and deviation from, planned procedures that led the subcontractor to cutting corners.

- Inadequate safety communication.

- Inadequate training related to hazards associated with specific tasks, such as working on pressurized pipe systems. 


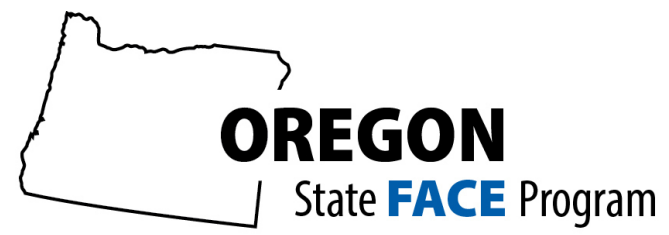

Fatality Assessment \& Control Evaluation

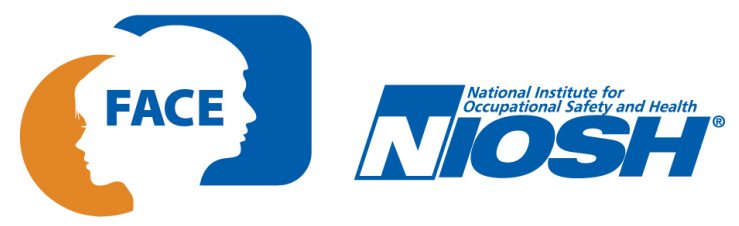

Oregon Institute of Occupational Health Sciences • Oregon Health \& Science University

3181 SW Sam Jackson Park Rd. L606 • Portland, OR 97239 • 503-494-3940

\section{RECOMMENDATIONS/DISCUSSION}

- Employers should not permit employees to perform repairs on pressurized water systems.

- Pipe systems should be pressure-tested and inspected before pipes are backfilled. Use checklists during tasks and inspection process to reduce risk of overlooking critical steps that could endanger workers.

- Prime contractors should establish a realistic project schedule in collaboration with subcontractors.

- Prime contractors should develop a communication plan so that subcontractors are made aware of project design modifications in a timely manner. Prime contractors and subcontractors should use the communication plan to work out how design changes will impact project schedule, so as not to compromise workplace safety.

- Employers should provide written procedures to employees prior to performing the work, and ensure employees receive adequate training so they understand the hazards and how to execute procedures safely.

\section{Recommendation \#1: Employers should not permit employees to perform repairs on pressurized water systems.}

Discussion: There are inherent dangers with pressurized systems and while there are no federal or Oregon OSHA standards that specify pressurized water systems should be depressurized prior to initiating maintenance or repairs, under the General Duty Clause of the Occupational Safety and Health Act (1970, as amended) employers are required to "furnish to each of his employees employment and a place of employment which are free from recognized hazards that are causing or are likely to cause death or serious physical harm to his employees". The employer was aware of the hazards of conducting repairs on pressurized water systems because the employer's HPT procedure item \# 8 specified that no work to repair leaks should be done while the test section is under pressure.

Recommendation \#2: Pipe systems should be pressure-tested and inspected before pipes are backfilled. Use checklists during tasks and inspection process to reduce risk of overlooking critical steps that could endanger workers.

Discussion: The prime contractor, subcontractor and inspectors should use and review task completion checklists. Tasks listed in a job hazard analyses (JHA) and job safety assessments (JSA) should correspond to the tasks listed on the task completion checklists.

Oregon Building Codes Division published a checklist with plumbing requirements, along with references to Oregon Plumbing Specialty Code (OBCD, 2020). The checklist is called the "Cite it, Write it Checklist." One of the listed benefits of this checklist is "Contractors can use the list as a guide to avoid common violations and check their work", and that the checklist contains "... a number of items to assist the inspector or contractor, including a brief description of the violation, the appropriate code citation and additional explanatory information." (OBCD, 2020).

The subcontractor's written hydrostatic pressure testing procedure contained two checklists for the testing, as well as forms for recording data from the test. In the systems checklist, one item listed was "All fittings/flanges/bolts tightened/torqued to spec?" The subsequent fields in the checklist table were "No", "Yes (Date \& Initial)", and "Comments". Item \#8 of the checklist specified that no work to repair leaks should be conducted while the test section of the pipe was under pressure. The checklist was not used during the hydrostatic pressure test because the Pressure Testing procedure was not included in the job safety manual for this construction project. 


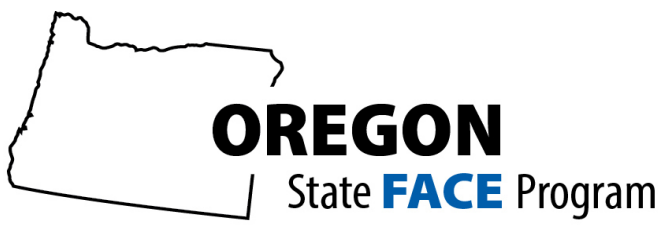

Fatality Assessment \& Control Evaluation

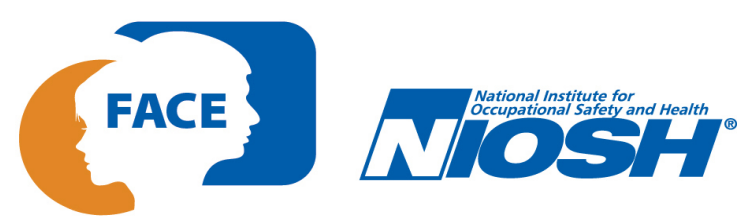

Oregon Institute of Occupational Health Sciences • Oregon Health \& Science University 3181 SW Sam Jackson Park Rd. L606 • Portland, OR 97239• 503-494-3940

The State Plumbing Inspector, the Fire Marshall, and the prime contractor's supervisor conducted a visual inspection of the vertical riser connection to the elbow, which was wrapped in plastic. After the inspection, the prime contractor authorized the subcontractor to backfill the area around the pipes. There was no indication a review of the Cite it, Write it checklist or something akin to the subcontractor's hydrostatic testing procedure checklist was reviewed. If those documents had been reviewed during the inspection process, it is likely the untightened torque shear bolts on the south riser would have been discovered and corrected before the pipes were backfilled.

Recommendation \#3: Prime contractor and subcontractors should collaboratively arrive at a realistic project schedule, and communicate when schedule changes.

Discussion: The prime contractor and subcontractors should develop and follow a communication plan before construction begins that includes how issues affecting schedule will be communicated and managed. A communication plan includes criteria and details regarding who is involved, who provides and receives notifications, and who is responsible for decision-making with regards to schedule changes.

In OSHA's Recommended Practices for Safety \& Health Programs in Construction, schedule changes are emphasized as a potential for creating new hazards in the workplace : “... unanticipated hazards can arise due to changes in project timelines, sequence of events, and the fast pace of some construction projects." (p.15).

The prime contractor's emphasis on the project schedule, even with the unplanned schedule delay due to the construction-phase design change, was an underlying condition of the incident that led to the fatality. The subcontractor, in trying to make-up time from the design change delay, created the situation of information overload for the supervisor, and miscommunication between the supervisor, the foreman, and the members of the excavation and hydrostatic testing crews. This led to the thrust block construction and backfill of the south vertical riser prior to the hydrostatic pressure test, which created the unanticipated hazard of an unsecured pressurized pipe.

A schedule delay due to a construction-phase design change should be considered an excusable delay for the subcontractor, as it was produced upstream of the subcontractor's purview. If the recommended communication plan were in place, the subcontractor may have felt more empowered to advocate for a more realistic schedule adjustment with the prime contractor. This would have provided time for the harried supervisor to pause and fully assess the work status of each subcontractor crew, which may have identified that the torque shear bolts on the south vertical riser had not been tightened, preventing the death of an employee.

Recommendation \#4: Prime contractors should develop and use a communication plan so that subcontractors are made aware of project design modifications in a timely manner. Prime contractors and subcontractors should use the communication plan to work out how design changes will impact project schedule, so as not to compromise workplace safety.

Discussion: The prime contractor should ensure any changes to the original construction project design is communicated to all subcontractors involved in the project. In this particular case, design changes communicated by the prime contractor after the subcontractor had completed a substantial amount of work, created a situation in which the subcontractor had to re-excavate and implement the project design changes. This not only added schedule pressure to the subcontractor, but also seem to negatively affect the communication amongst the subcontractor crews, which was an underlying cause of the workplace fatality. 


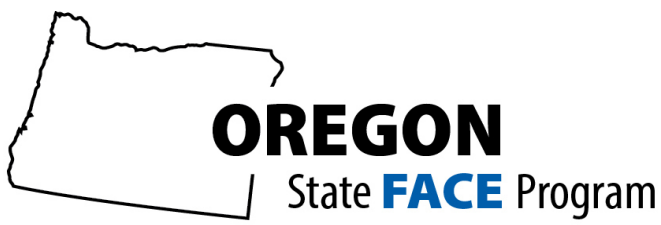

Fatality Assessment \& Control Evaluation

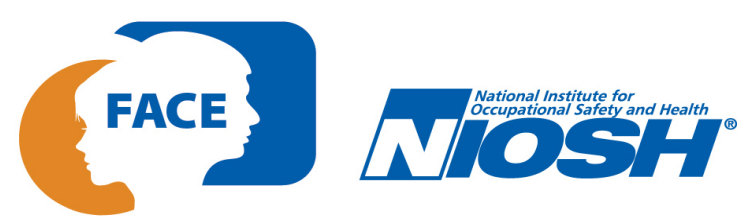

Oregon Institute of Occupational Health Sciences • Oregon Health \& Science University 3181 SW Sam Jackson Park Rd. L606 • Portland, OR 97239• 503-494-3940

Design changes can occur at any point in the design-to-build process. Depending on the scale, design changes during the build phase of a project can be expensive, affect the project schedule, and create unanticipated workplace safety hazards. Changes to the design can be triggered by several factors including changes directed by project owner, mistakes uncovered in initial architectural plans, staffing changes, building material quality and/or delivery issues, hydrology problems encountered during excavation, and/or labor shortages. Regardless of what precipitated the design change, communicating design changes to subcontractors is the responsibility of the prime contractor (29 CFR. 1926. $16(b$ and $c))$.

The Occupational Safety and Health Administration (OSHA) published "Recommended Practices for Safety \& Health Programs in Construction (OSHA, 2016). To establish effective communication, this guidance document highlights that "the general contractor establishes and implements procedures to exchange information with contractors, subcontractors and staffing agencies about hazards present on the job site and the measures that have been implemented to prevent or control such hazards." (p.32). In accordance with this guidance, design changes during the construction phase should be communicated to the subcontractors in writing, allowing time for any necessary language translations.

If the prime contractor had communicated the design changes to the subcontractor in a timely manner, it is likely the subcontractor would have been able to accommodate the changes without impacting the project schedule, which could have prevented the subcontractor crews from backfilling the fire suppression pipes and installing the thrust blocks before the hydrostatic pressure test had been conducted.

\section{Recommendation \#5: Employers should provide written procedures to employees prior to performing the work, and} endure employees receive adequate training so they understand the hazards and how to execute procedures safely.

Discussion: The employer should ensure employees have adequate training on the hazards associated with each task they perform at work, and keep records of such training up to date.

The General Safety and Health provisions for the construction industry of both federal OSHA (29 CFR 1926.20(b)(4)) and Oregon OSHA (OAR 437.003.0920) require that general contractors and subcontractors "ensure that only employees qualified by training and experience operate equipment and machinery."

The General Safety and Health provisions for the construction industry of both federal OSHA (29 CFR 1926.20(f)(2)) and Oregon OSHA (OAR 437.003.0920) also require employers to provide training to employees on "hazards and related matters [and] the employer must train each affected employee in the manner required by the standard."

With regards to employee training record retention, under federal OSHA, an employer is required to retain employee training records for Lockout/Tagout, use of personal protective equipment (PPE), hazard communication, process safety management involving certain quantities of hazardous materials, working with asbestos, emergency action plans, working in a confined space, bloodborne pathogens, respiratory protection, electrical safety, and powered industrial trucks. However, there is no requirement under federal OSHA regarding retention of training records for general health and safety. Both federal OSHA and Oregon OSHA recommend maintaining an employee's training records while the employee is employed with the employer.

The subcontractor had a written procedure for the hydrostatic pressure test, but it was not made available to the employees performing the test, including the decedent. During the investigation, the subcontractor provided employee 


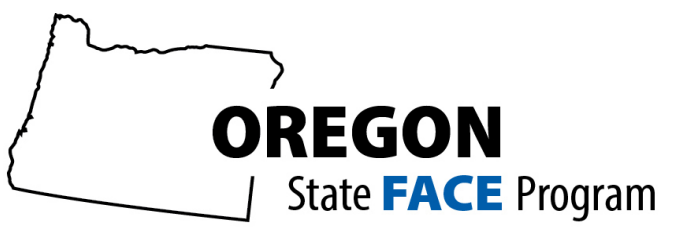

Fatality Assessment \& Control Evaluation

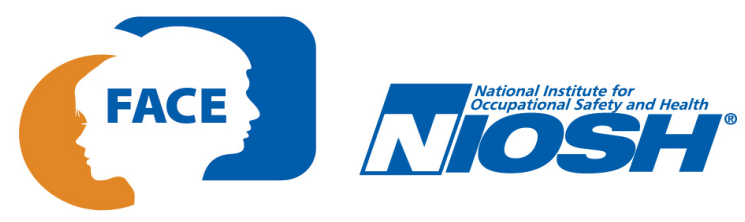

Oregon Institute of Occupational Health Sciences • Oregon Health \& Science University

3181 SW Sam Jackson Park Rd. L606 • Portland, OR 97239 • 503-494-3940

training logs to the OSHA SCO, but there was also no evidence the decedent received training in performing a hydrostatic pressure test.

\section{ADDITIONAL RESOURCES}

NIOSH Directory of Construction Resources. https://www.cdc.gov/niosh/construction/

Recommended Practices for Safety \& Health Programs in Construction". OSHA Publication 3886, October 2016.

https://www.osha.gov/Publications/OSHA3886.pdf.

OSHA Training Requirements in OSHA Standards.

OSHA Training and Reference Materials Library for Construction. https://www.osha.gov/training/library/materials

Oregon OSHA Construction Depot.

https://osha.oregon.gov/pubs/newsletters/constructiondepot/OSHAConstructionDepot/2014/10/who-is-

responsible.html

Oregon Institute of Occupational Health Sciences Resource Directory. https://apps.ohsu.edu/oregon-instituteoccupational-health-sciences/resources/

The Center for Construction Research and Training (CPWR), Electronic Library of Construction Occupational Safety \& Health (ELCOSH). http://www.elcosh.org/index.php

\section{DISCLAIMER}

Mention of any company or product does not constitute endorsement by Oregon FACE program (OR-FACE) or the National Institute for Occupational Safety and Health (NIOSH). In addition, citations to websites external to OR-FACE or $\mathrm{NIOSH}$ do not constitute endorsement of the sponsoring organizations or their programs or products. Furthermore, ORFACE or NIOSH are not responsible for the content of these websites. All web addresses referenced in this document were accessible as of the publication date.

\section{REFERENCES}

Weather Underground [2018]. Pendleton, OR Weather History. The Weather Channel Interactive, Inc., https://www.wunderground.com/history/daily/KPDT/date/2018-3-6. Accessed February 28, 2020.

EBAA Iron, Inc. "Megalug Series 1100 Mechanical Joint Restraint for Ductile Iron PVC Pipe". EBAA, Eastland, TX. www.ebaa.com. Accessed March 10, 2020.

OSHA, 2016. "Recommended Practices for Safety \& Health Programs in Construction". OSHA Publication 3886, October 2016. https://www.osha.gov/Publications/OSHA3886.pdf.

OBCD, 2020. Cite it, Write it Checklist, Plumbing Code Program. Oregon Building Codes Division. Accessed April 14, 2020. https://www.oregon.gov/bcd/codes-stand/Pages/Plumbing.aspx

OSHA, 2015. "Training Requirements in OSHA Standards". OSHA Publication 2254-09R, 2015.

https://www.osha.gov/Publications/osha2254.pdf. 


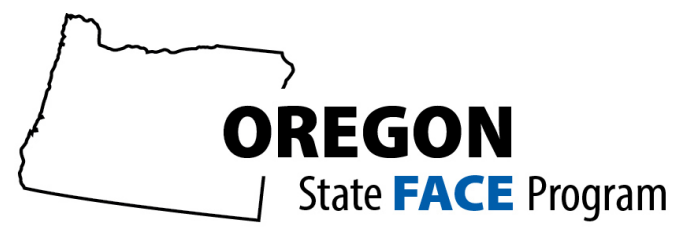

Fatality Assessment \& Control Evaluation

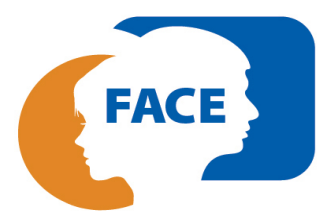

NosH

Oregon Institute of Occupational Health Sciences • Oregon Health \& Science University

3181 SW Sam Jackson Park Rd. L606 • Portland, OR 97239 • 503-494-3940

\section{FACE INVESTIGATION INFORMATION}

This investigation was conducted by Barbara Hanley, MPH, Research Associate, Fatality Investigations Team, Oregon FACE (OR-FACE) at Oregon Institute of Occupational Health Sciences at Oregon Health Sciences University (OHSU). The report was peer-reviewed by Nikolas Smart OR-FACE Project Coordinator, and Dr. Ryan Olson, Professor and CoDirector, Oregon Healthy Workforce Center - a NIOSH Center of Excellence in Total Worker Health ${ }^{\circledR}$.

\section{ACKNOWLEDGEMEMENT}

The OR-FACE Program would like to acknowledge the staff of the Oregon Department of Consumer and Business Services, and Jeffrey D. Bartunek, Oregon OSHA Senior Safety Compliance Officer, Pendleton Office, for providing assistance and information for this investigation. 